\section{Adherence and side effects of three ferrous sulfate treatment regimens on anemic pregnant women in clinical trials}

\author{
Adesão e efeitos colaterais em ensaio clínico \\ comparando três esquemas de tratamento \\ com sulfato ferroso em gestantes anêmicas
}

\footnotetext{
${ }_{1}$ Instituto de Medicina Integral Professor Fernando Figueira, Recife, Brasil.

2 Universidade de

Pernambuco, Recife, Brazil.

Correspondence

A. I. Souza

Departamento de Pesquisa, Instituto de Medicina Integral Professor Fernando Figueira.

Rua dos Coelhos 300, Recife PE 50070-550, Brasil ariani@imip.org.br
}

\begin{abstract}
The objective of this study was to analyze adherence and side effects of three iron supplement regimens (ferrous sulfate) on anemic pregnant women. The clinical trial involved 150 women between the 16th and 20th gestational weeks, at low obstetric risk and with hemoglobin concentration of between 8.0 and $11.0 \mathrm{~g} / \mathrm{dL}$. Treatment was provided by ferrous sulfate with $60 \mathrm{mg}$ of elemental iron during $16( \pm 1)$ weeks, in three regimens: single tablet a week $(n=48) ;$ single tablet twice a week $(n=53)$ or single tablet a day $(n=49)$. The outcomes were adherence, assessed through interviews and by counting tablets, and side effects, according to patient information. The adherence showed a declining trend (92\%, 83\% and $71 \% ; p=0.010$ ) and the side effects revealed a growing trend $(40 \%, 45 \%$ and $71 \% ; p=0.002)$ as the dosage increased. Diarrhea and epigastric pain were significantly associated with the dose administered ( $p=0.002)$. These results suggest that in anemic pregnant women, complaints are directly proportional and the compliance is inversely proportional to the amount of medicinal iron.
\end{abstract}

Anemia; Iron Deficiency; Ferrous Sulfate; Pregnant Women

\author{
Ariani Impieri de Souza 1 \\ Malaquias Batista Filho 1 \\ Cristiane Campello Bresani 1 \\ Luiz Oscar Cardoso Ferreira 2 \\ José Natal Figueiroa 1
}

\section{Background}

Iron-deficiency anemia is currently the most prevalent nutritional deficiency in the world. The condition is widely distributed across all continents and affects every socioeconomic group. Nevertheless, its frequency and severity are much greater among the most disadvantaged social strata ${ }^{1}$. Although host susceptibility is universal, women of reproductive age and children, experiencing rapid body growth, are the biological groups that are most vulnerable 2 .

Despite the epidemiological importance of anemia, international goals for combating this health problem have been quite modest. Thus, while the Summit Meeting of New York (1990) determined that control of primary iodine and vitamin A deficiency would be a decennial commitment, the aim proposed for anemia was limited to reducing its prevalence by a third among women of childbearing age 2 . In 1996, children under five, adolescents and pregnant women began to be incorporated into the proposal ${ }^{3}$. The production and consumption of bio-available iron, the industrial enrichment of flour with iron salts and folate, and ultimately the use of medicinal iron to protect high-risk population groups were recommended strategic actions 4 .

According to the World Health Organization (WHO), supplement programs based on medicinal iron compounds provide a short-term effectiveness of $70 \%$ when correctly followed. Mean- 
while, fortification of food vehicles with iron and folate can achieve an effective long-term result of $93 \% 1$. However, despite recommendations for these products and their high effectiveness, indications show that control programs have not yet fulfilled their objectives in the time proposed. Therefore, the goals of the United Nations are still far from being obtained 3,5.

This situation was evidenced in a report from the Division of the Central Asian Republics and Kazakhstan issued by the United Nations Children's Fund (UNICEF) that elevated the region's problem to a level of "public health crisis," highlighting that $60 \%$ of children and $80 \%$ of mothers had anemia. Failure of the program to control anemia in Central and Eastern Europe, the Commonwealth of Independent States and the Baltic States was emphasized, where the "severe and growing" problem could affect 40 to 50 per cent of pregnant women and 50 per cent of children under five 3,4 . This rate is higher than the estimate of the Pan-American Health Organization (PAHO) for Brazil which stands at around 30\% in the under fives 4 . However, a growing trend in the magnitude of the problem has also been observed in Brazil 6.

Among the major factors that contribute towards the partial success of goals and actions proposed and carried out by the health sector, poor patient adherence to preventive and curative treatment regimens plays a significant role. It is widely acknowledged that one of the most common reasons for poor adherence and consequent discontinuation of treatment is the complaint of unpleasant side effects, particularly related to the digestive tract $1,2,3,7$.

However, despite growing evidence that lower doses promote high efficiency 8,9, the WHO 1 persists with daily dose recommendations of $60 \mathrm{mg}$ of elemental iron for preventive and 120 mg for therapeutic purposes. Such doses have been associated with side effects in pregnant women.8,9 In the last two decades, alternative treatment regimens for control of anemia using intermittent doses of iron salts (once or twice per week) have been compared to daily traditional regimens with promising results 8,9,10,11,12.

Adverse reactions, including lack of appetite, epigastric pain, nausea, vomiting, dark colored stools, abdominal cramps and constipation have been described by more than $10 \%$ of iron salt users. Heartburn, diarrhea, discolored urine and temporary staining of teeth (especially in children) may occur in 1\%-10\% of cases. Local irritation due to contact with the gastrointestinal mucosa may occur in less than $1 \%$ of treatments. Other uncommon consequences of iron supplement use are hypersensitivity, intoxication (accidental or intentional) and inhibited absorption of some medications, such as antimicrobials $13,14,15,16$.

Under the circumstances, a crucial issue of research is to reduce or eliminate the adverse effects caused by treatment of the anemia 8,9. Therefore, an interesting field of investigation would be to use different chemical compounds of medicinal iron or resort to different combinations and dose alternatives to address the problem. The current clinical trial proposed to analyze adherence to three treatment regimens with ferrous sulfate, recording possible side effects among pregnant women.

It is worth highlighting that the pregnant population is among the highest risk segment for iron deficiency and is considered a top priority for public policies. However, the prevalence of anemia is still high and there is widespread uncertainty in the field of study of this condition. A number of studies have examined the use of supplemental iron in pregnant women. However, few studies that address the side effects and adherence of iron supplements exist in the literature 8,9 .

\section{Objective}

To analyze adherence to and side effects of three iron supplement regimens with ferrous sulfate orally administered to anemic pregnant women.

\section{Methods}

This article shows no published data from a primary clinical trial about the effectiveness of three regimens using ferrous sulfate in pregnant women 10 . The actual outcomes were: (1) a report of any of the side effects during at least one follow-up visit and (2) lack of adherence to treatment.

Pregnant women who spontaneously sought prenatal consultation at the Outpatient Facility of the Women's Care Center at the Instituto de Medicina Integral Professor Fernando Figueira (IMIP) from May 2000 to June 2001 were recruited for the study. IMIP is a tertiary hospital, located in the Northeastern region of Brazil. Pregnant women carrying a single fetus between the 16th and 20th gestational week, with a hemoglobin concentration $(\mathrm{Hb})$ between 8.0 and $11.0 \mathrm{~g} / \mathrm{dL}$ and a low obstetric risk (absence of uterine disease, heart disease, diabetes mellitus, hypertension and kidney disease) were selected.

Women were excluded from either the sample selection if they had used medication containing 
iron in the last 60 days or from the study followup if: (1) they used other iron-containing medication, (2) there was a disease that converted the pregnancy to a high-risk status (gestational diabetes, gestational hypertension, preterm delivery), (3) there was a reduction higher or equal to $0.5 \mathrm{~g} / \mathrm{dL}$ in $\mathrm{Hb}$ value, achieving levels lower than $10.0 \mathrm{~g} / \mathrm{dL}$ in the 8 th week of iron supplement use. These pregnant women were treated with standard daily doses.

The intervention was made using ferrous sulfate heptahydrated solution $\left(\mathrm{FeSO}_{4} 7 \mathrm{H}_{2} \mathrm{O}\right)$, Ariston Ferrous Sulfate tablets (Inds Quims e Farms $L T D A$ ), in 300mg tablets (60mg of elemental iron), as analyzed by the Center for Quality Control of Drugs in the Department of Pharmaceutical Sciences at the Universidade Federal de Pernambuco (Brazil). The patients were assigned to take the medication orally, spaced at least 30 minutes apart from meals and preferably before bedtime during $16( \pm 1)$ consecutive weeks, in one of the three treatment regimens: 1 (weekly) - one tablet once a week; 2 (twice weekly) - one tablet on two non-consecutive days of the week, with a three to four day interval; 3 (daily) - one tablet daily. This iron salt was chosen because it was the most widely recommended and common form of iron used. It is a low-cost and safe medication (risk factor category A during pregnancy), with a good relative absorption 13,17 .

Gestational age was investigated by the date of last menstruation and confirmed by ultrasound. The $\mathrm{Hb}$ was measured using the Coulter automatic counter (model T 890) at three time periods: entry, 8th and 16th weeks of follow-up.

To characterize the sample population, the following variables were determined: school education, age, number of pregnancies, nutritional status, serum ferritin, and the presence of intestinal parasitic infections and urinary infection. Nutritional status was measured by body mass index, according to Atalah et al.18 criterion. Serum ferritin was measured at the study entry by the Cobas method Core Ferritin EIA Roche. Intestinal parasites were investigated by means of a single stool specimen for the Hoffman method; urinary infection was tested by urine culture.

Side effects analyzed were related to common gastrointestinal symptoms: diarrhea, constipation and epigastric/abdominal pain, or any selfreported symptoms that appeared after using the iron supplement. Treatment adherence was considered inadequate when the pregnant woman failed to comply with the treatment plan: (1) in regimen 1 - missed taking the weekly tablet for more than two weeks; (2) in regimen 2 - missed taking at least one weekly tablet for more than two weeks; and (3) in regimen 3 - missed tak- ing more than three tablets in the same week, for more than two weeks.

Follow-up was carried out on a monthly basis, when tablets were distributed, checking for adherence (interview and tablet count) and reinforcing instructions. The women who reported complaints were informed about these side-effects and were allowed to decide if they wished to continue with the study. In the postpartum period, all women were instructed to maintain a daily iron supplement until returning to the family planning outpatient facility.

A convenience sample was used and allocation was consecutively and casually unblinded by the main researcher to each of the three experimental groups. The sample size was calculated in the primary research ${ }^{10}$, aimed at detecting a difference of $0.5 \mathrm{~g} / \mathrm{dL}$ in the mean $\mathrm{Hb}$ after treatment, according to Kirkwood's formula with an error of 0.05 , power of 0.80 and variances of 0.80 . A sample of 50 women for each group, totaling 150 participants was therefore estimated. The professionals responsible for laboratory tests and data analysis were blinded to treatment assignments.

The ANOVA test was used to compare means, the Kruskal-Wallis test was used to compare medians and the trend test 2 was used to compare rates. The significance level adopted was $5 \%$ in all tests. Study data was entered and double-entry was performed. Data was analyzed using the following software: Epi Info v.6.04d (Centers for Disease Control and Prevention, Atlanta, USA) and Minitab v. 11 (Minitab Inc., State College, USA).

Researchers complied with the ethical postulates of the Helsinki Declaration and its subsequent amendments for research involving human subjects, in addition to the terms of Resolution $n^{\circ}$. 196/96 from October 1996 of the National Health Council of Brazil. Informed free consent was obtained from each participant and the person responsible if the pregnant woman was under 18 years old. The project was submitted to the Research Ethics Committee of the institution where it was conceived, and registered under number 016/2001.

\section{Results}

Between May 2000 and June 2001, 476 pregnant women were potential candidates for the study and 215 pregnant women met the eligibility criteria. Of these women, $191(88.8 \%)$ returned to the health service between the 20th and 24th gestational weeks, agreed with the study and were allocated to three treatment groups by order of arrival. 41 participants were lost to follow-up 
(21.5\%) due to spontaneous withdrawal or exclusion from the study, resulting in a final sample of 150 pregnant women: 48 in treatment regimen 1; 53 in treatment regimen 2 and 49 in treatment regimen 3 (Figure 1).

The reasons why 41 pregnant women withdrew or were excluded from the study are described in the publication of the primary trial 10 . No withdrawal from treatment was due to adverse effects in treatment regimens 1 and 2. However, of the 14 women in group 3 who discontinued treatment, seven were due to symptoms of diarrhea or epigastric pain. These women were conduced to customary prenatal care. The losses were equally distributed among the three groups and no statistically significant difference was noted between the pregnant women who withdrew from the study and those who remained until the end of the experiment, regarding control variables 10 .
The three treatment groups were similar regarding age, school education, nutritional status, number of pregnancies, gestational age, intestinal parasitic disease, urinary tract infection, hemoglobin concentration and serum ferritin (Table 1).

Of the 150 pregnant women who completed the treatment, 123 had adequate adherence. The adherence rate showed a declining trend with increasing frequency of doses prescribed, as follows: 44/48 (92\%); 44/53 (83\%) and 35/49 (71\%); $(\mathrm{p}=0.010) .78$ pregnant women who continued treatment complained of one or more side effects: 19/48 for treatment regimen 1 (weekly), 24/53 for treatment regimen 2 (twice weekly) and 35/49 for treatment regimen 3 (daily). There was a statistically significant trend towards increasing frequency of intolerance symptoms with increasing doses of medicinal iron $(\mathrm{p}=$ 0.002 - Table 2)

Figure 1

Flow chart allocating pregnant study participants. Women's Care Center of the Instituto de Medicina Integral Professor Fernando Figueira (IMIP). Recife, Pernambuco State, Brazil, 2000/2001.

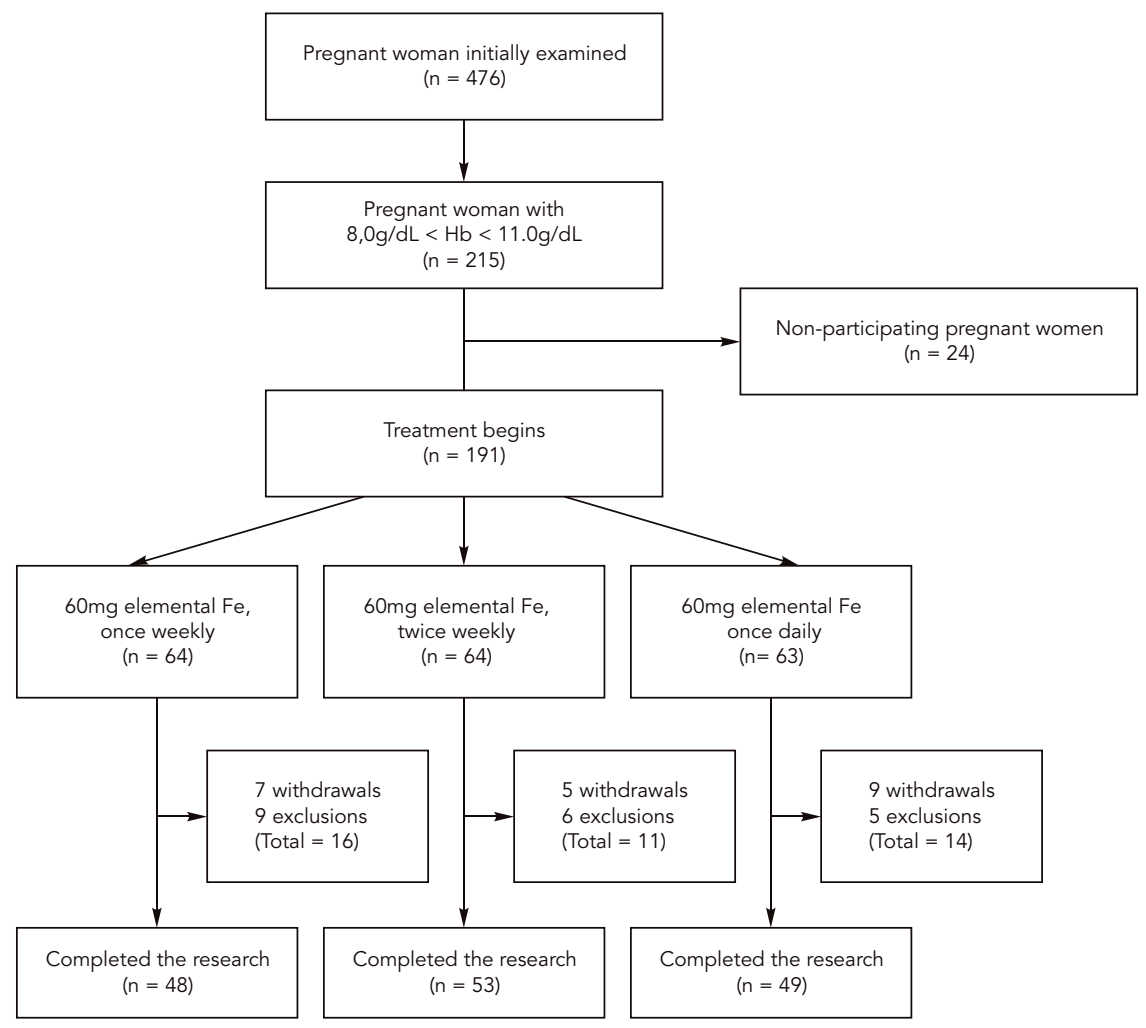


Biological, social and clinical characteristics of the pregnant women according to iron treatment regimen. Women's Care Center at the Instituto de Medicina Integral Professor Fernando Figueira (IMIP), Recife, Pernambuco State, Brazil, 2000/2001.

\begin{tabular}{|c|c|c|c|c|}
\hline \multirow[t]{3}{*}{ Variables } & \multicolumn{4}{|c|}{ Treatment regimen } \\
\hline & \multirow{2}{*}{$\begin{array}{c}\text { Weekly }(n=48) \\
\text { Parameter * }\end{array}$} & \multirow{2}{*}{$\begin{array}{c}\text { 2x/week }(n=53) \\
\text { Parameter * }\end{array}$} & \multirow{2}{*}{$\begin{array}{l}\text { Daily }(n=49) \\
\text { Parameter * }\end{array}$} & \multirow[t]{2}{*}{$\mathrm{p}$ value ** } \\
\hline & & & & \\
\hline Median age (years) & $21(8.5)$ & $22(7)$ & $22(8)$ & 0.306 \\
\hline Median school education (years) & $9(5)$ & $9(4)$ & $9(4)$ & 0.642 \\
\hline Median number of pregnancies & $1(1)$ & $1(1)$ & $1(1)$ & 0.453 \\
\hline \multicolumn{5}{|l|}{ Nutritional status (\%) } \\
\hline Low weight & 27.1 & 30.2 & 32.7 & \\
\hline Adequate weight & 54.2 & 47.2 & 46.9 & \\
\hline Overweight/obese & 18.8 & 22.7 & 20.4 & 0.942 \\
\hline Mean gestational week & 17.3 & 17.5 & 17.3 & 0.586 \\
\hline Median ferritin (ng/mL) & $30.2(44.1)$ & $37.1(47.4)$ & $52.9(68.3)$ & 0.344 \\
\hline Mean hemoglobin (g/dL) & $10.2(0.5)$ & $10.2(0.6)$ & $10.1(0.6)$ & 0.518 \\
\hline Urinary infection (\%) & 16.7 & 26.9 & 32.7 & 0.188 \\
\hline Intestinal parasites (\%) & 44.7 & 31.3 & 41.7 & 0.370 \\
\hline
\end{tabular}

* Standard deviation for means and interquartile range for medians;

** ANOVA for means, Kruskal-Wallis for medians and $\chi^{2}$ for rates.

Table 2

Side effects and adherence of pregnant women who completed the study according to iron treatment regimen. Women's Care Center at the Instituto de Medicina Integral Professor Fernando Figueira (IMIP), Recife, Pernambuco State, Brazil, 2000/2001.

\begin{tabular}{|c|c|c|c|c|c|c|}
\hline \multirow[t]{2}{*}{ Treatment regimen } & \multicolumn{2}{|c|}{ Side effects * } & \multirow[t]{2}{*}{ OR (95\%IC) } & \multicolumn{2}{|c|}{ Adequate adherence ** } & \multirow[t]{2}{*}{ OR $(95 \%$ IC) } \\
\hline & $\mathrm{n}$ & $\%$ & & $\mathrm{n}$ & $\%$ & \\
\hline Weekly $(n=48)$ & 19 & 39.6 & 1.0 & 44 & 91.6 & 1.0 \\
\hline $2 x /$ week $(n=53)$ & 24 & 45.3 & $1.3(0.6-2.8)$ & 44 & 83.0 & $0.4(0.1-1.5)$ \\
\hline Daily $(n=49)$ & 35 & 71.4 & $3.8(1.6-8.9)$ & 35 & 71.4 & $0.2(0.1-0.7)$ \\
\hline Total $(n=150)$ & 78 & 52.0 & & 123 & 82.0 & \\
\hline
\end{tabular}

Trend $\chi^{2:}{ }^{\star} p=0.002 ;{ }^{\star \star} p=0.010$

Regarding side effects diarrhea and epigastric/abdominal pain were the symptoms that showed a significant association with the dose administered ( $p=0.002$ for both symptoms), while constipation was equally present in the three treatment regimens. In the daily treatment regimen, 10 women had more than one complaint, resulting in a total of 45 complaints among the 35 symptomatic pregnant women of this group, a fact that was not repeated in the other treatment regimens (Table 3 ).

At the end of follow-up, there was no difference in the occurrence of intestinal parasitic infections between pregnant women with and those without side effects $(p=0.437)$.

\section{Discussion}

Two large and current systematic reviews of iron supplements used by pregnant women were unable to draw definitive conclusions about the side effects, due to the scarcity of published data 8,9 . Reveiz et al. 9 found 17 controlled randomized trials in the last four decades, totaling 2,578 women, and only one trial evaluated the side effects associated with oral iron ${ }^{19}$. Pena-Rosas \& Viteri 8 analyzed 40 randomized and "quasi-randomized" trials (12,706 women) in the last five decades, seven of which evaluated side effects and only two that were considered high-quality trials 20,21. It is highlighted that none of these studies com- 
Symptoms experienced by pregnant women that completed the study, according to iron treatment regimen. Women's Care Center at the Instituto de Medicina Integral Professor Fernando Figueira (IMIP), Recife, Pernambuco State, Brazil, $2000 / 2001$.

\begin{tabular}{|c|c|c|c|c|c|c|c|}
\hline \multirow[t]{3}{*}{ Symptoms } & \multicolumn{7}{|c|}{ Treatment regimen } \\
\hline & \multicolumn{2}{|c|}{ Weekly } & \multicolumn{2}{|c|}{$2 x /$ weekly } & \multicolumn{2}{|c|}{ Daily } & \multirow{2}{*}{$\begin{array}{l}\text { Trend } \\
\text { test } \chi^{2}\end{array}$} \\
\hline & $\mathrm{n}$ & $\%$ & $\mathbf{n}$ & $\%$ & $\mathrm{n}$ & $\%$ & \\
\hline Constipation & 9 & 47.4 & 9 & 37.5 & 10 & 22.2 & 0.833 \\
\hline Diarrhea & 5 & 26.3 & 6 & 25.0 & 17 & 37.8 & 0.002 \\
\hline Epigastric pain & 5 & 26.3 & 9 & 37.5 & 18 & 40.0 & 0.002 \\
\hline Total & 19 & 100.0 & 24 & 100.0 & 45 * & 100.0 & - \\
\hline
\end{tabular}

* 45 complaints from 35 patients in group 3.

pared the side effects in different oral iron supplements. In addition, the majority of studies using oral iron were marked by high loss rates, pointing to the importance of focusing on side effects and adherence to the frequently prescribed treatments 8,9 .

To avoid misconceptions, several considerations about the current trial should be addressed. Non-randomization of the sample may lead to selection bias. However, sampling and allocation by order of arrival at the health service (convenience sampling) guarantee randomness in a clinical setting ${ }^{22}$. The fact that the researcher and participant were not blinded may have induced and influenced the report of side effects. Nevertheless, unblinding was important to investigate adherence with greater veracity, since the complexity of the treatment regimen administered could influence its correct use. Losses of $21.5 \%$ were considered acceptable 22 and did not affect comparability among groups 10 . Furthermore, these losses could partly represent trial outcome, since they were strongly motivated by the side effects in the group taking the highest dose of oral iron. 10

The adherence rate was satisfactory in the three treatment groups, although it significantly decreased with increasing doses of iron supplements. This downward trend of adherence has frequently been described $12,15,23,24,25,26$. It is a relevant and critical issue when seeking an alternative to improve the effectiveness of treatment measures for controlling one of the most important nutritional problems during pregnancy 3,4 .

It is important to note that adequate adherence to treatment with iron salts has also been determined in other clinical trials, although adherence criteria were considerably diversified and not standardized, making it more difficult to properly understand the problem. Kumar et al. 15 reported that $90 \%$ of the 98 supplemented pregnant women did not need to discontinue treatment because of side effects; Zavaleta et al. 27 commented that 600 pregnant women supplemented with iron and folic acid consumed an average of $85 \%$ of the tablets prescribed; O'Brien et al. 28 found that in 28 pregnant women treated, more than $90 \%$ used iron at least five days a week. All these authors administered iron orally and on a daily basis.

It should be emphasized that the main aim of most experiments using oral medicinal iron, including the original clinical trial from which this study was specifically designed, is to evaluate the effectiveness of treatment. Experiments take place under conditions favorable to adherence (information, monitoring, motivation), minimizing a confounding effect on response to treatment. Nevertheless, even if information bias contributed to the high levels of compliance found in this study, a decreasing trend in compliance with increasing doses of ferrous sulfate was observed. Clearly, if this fact does not result from differences in follow-up among the three intervention groups, it could convey a dose-dependent effect between adherence and treatment.

On the other hand, Ekström et al. 14, with the primary purpose of evaluating adherence, attempted to undo the effect of strict supervision by using an electronic device to record the opening of the tablet containers in a follow-up of 87 pregnant women. These authors observed an adherence rate of $42 \%$, which is probably closer to the real adherence of community-based supplementation programs. The WHO 1 emphasizes that adherence is usually poor when supplements are not supervised. Poor treatment adherence combined with the negative influence exerted by side effects might help to explain why most treatments fail to control pregnancy anemia 1 . 
In this study, the side effects, that could be chronologically attributed to iron supplementation were constipation, diarrhea and abdominal/epigastric pain. Other symptoms, such as heartburn and nausea could not be clearly distinguished from pre-existing pregnancy complaints. A dose-dependent effect between rates of diarrhea and abdominal/epigastric pain was observed with doses of iron compounds.

It is noteworthy that the potential for confounding between side effects and symptoms of intestinal parasitic diseases was unlikely in the pregnant women studied, since the frequency of positive stool testing for parasites was similar in women with and without side effects.

Similar to the current assessment, a study conducted by Kumar et al. 15 with 220 pregnant women found $21.3 \%$ of complaints associated with oral iron: diarrhea, vomiting, constipation and dyspepsia. Likewise, gastrointestinal side effects were also more common in a study by Ekström et al. 14 .

In this clinical trial, decreased adherence was accompanied by an increase in diarrhea and epigastric pain with increasing iron doses in the three study groups. These aspects could be attributed to a local and dose-dependent effect of iron compounds on the digestive tract, affecting the adherence to treatment 16 .

A dose-dependent effect was also described by Ekström et al. 14 where administered doses of controlled-release (50mg of elemental iron) or conventional (120mg of elemental iron) supplements, with $12 \%$ and $22 \%$ of side effects, respectively. These authors observed that the combination of symptoms was more frequent in the conventional treatment group. Furthermore, adherence to controlled-release and conventional iron supplements was $61 \%$ and $42 \%$, respectively. For both groups, adherence was always one-third lower among those who had symptoms. In addition, there was a positive dose-response effect between adherence and hemoglobin concentration at the end of 12 weeks of supplementation.

In contrast to the hypotheses discussed, Cogswell et al. 20 and Meier et al. 29 found no differences in the occurrence of side effects or adherence problems in randomized placebo-controlled trials when comparing the placebo group with daily supplementation (30mg and $60 \mathrm{mg}$ of elemental iron, respectively). However, excessive losses and a short follow-up period in the study conducted by Cogswell et al. 20 as well as the limited sample in the study by Meier et al. 29 might have contributed to these results.

Makrides et al. 30 also found no differences in the occurrence of adverse effects when comparing the use of a placebo with an iron supplement (20mg of elemental iron daily) among 386 pregnant women. However, these authors reported that women switching to a high-dose treatment ( $\geq 80 \mathrm{mg} /$ day) had dark colored and hard stools.

Furthermore, the association of side effects and adherence with effectiveness of oral iron supplement programs is unavoidable. It is noteworthy that pregnant women in the clinical research setting of this study achieved good adherence to treatment. The adherence was close to the effectiveness suggested by the WHO (70\%) 1 even in the group taking higher iron doses.

Assuming that the general population does not live under adequate conditions of basic health care in developing regions, it is likely that adherence is one of the main obstacles to the effectiveness of unsupervised programs aimed to combat iron-deficiency anemia. In our region, Ferreira et al. 31 observed this fact in a community-based experiment for controlling anemia with oral iron in children younger than two years of age. In this context, perhaps the unpleasant symptoms were secondary determining factors, provided that the correct distribution and availability of supplements, information, counseling, motivation, and monitoring were basic operational factors that preceded and simultaneously resolved the adherence problem.

Similarly, in a non-systematic review, Cardoso \& Penteado 32 discussed the same aspects and cited the National Iron Supplementation Program of India in the 80s as an example where the mean discontinuation rate ranged from 9 to $87 \%$. Over $80 \%$ of the subjects blamed the lack of iron supplements and less than $3 \%$ blamed the side effects.

In conclusion, a direct relationship between the amount of medicinal iron administered and the frequency of diarrhea and epigastric pain was demonstrated in low-risk anemic pregnant women. An inverse relationship between the amount of medicinal iron administered and the ratio of adherence to ferrous sulfate supplementation was shown.

It seems reasonable to suggest that clinical studies concerning iron supplementation should focus on treatment adherence and side effects. Studies that assess policies, services and actions of programs aimed at combating iron-deficiency anemia need to be carried out to examine the most structural aspects of the problem. 


\section{Resumo}

O objetivo deste estudo foi analisar a adesão e os efeitos colaterais de três esquemas de suplementação com sulfato ferroso em gestantes anêmicas. $O$ ensaio clínico incluiu 150 mulheres entre a 16a e 20a semanas de gestação, de baixo risco obstétrico e com concentração de hemoglobina entre 8,0 e 11,0g/dL. A intervenção foi realizada com $60 \mathrm{mg}$ de ferro elementar, durante 16 $( \pm 1)$ semanas, em três esquemas: uma drágea semanal $(n=48)$; uma drágea duas vezes por semana $(n=53)$ ou uma drágea diariamente $(n=49)$. Os desfechos foram adesão, verificada por entrevista e contagem das drágeas, e efeitos colaterais auto-relatados pelas pacientes. A adesão apresentou tendência declinante (92\%, 83\% e 71\%; $p=0,010)$ e os efeitos colaterais, ascendente $(40 \%, 45 \%$ e $71 \% ; p=0,002)$ com o aumento da dose prescrita. Diarréia e dor epigástrica estiveram significativamente associadas à dose administrada ( $p$ $=0,002)$. Os resultados sugerem que em gestantes anêmicas as queixas e a adesão ao tratamento com sulfato ferroso são, respectivamente, direta e inversamente proporcionais à quantidade do ferro medicamentoso.

Anemia; Deficiência de Ferro; Sulfato Ferroso; Gestantes

\section{Contributors}

A. I. Souza, M. Batista Filho e L. O. C. Ferreira participated in project design and study implementation, procuring financial resources, database development, statistical analysis of data and writing of the clinical trial. C. C. Bresani participated in statistical analysis of data and final writing of the current article. J. N. Figueiroa participated in project design, database development and statistical analysis of data of clinical trial.

\section{Acknowledgments}

This study was financially supported by the Centro Colaborador em Alimentação e Nutrição - Nordeste I (CECAN). Ariani I. Souza, Malaquias Batista Filho, Cristiane C. Bresani, Luiz O. C. Ferreira and José Natal Figueiroa have no financial or personal conflicts of interest to report.

\section{References}

1. World Health Organization (WHO). Iron deficiency anemia: assessment, prevention and control - a guide for programme managers. Geneva: World Health Organization; 2001.

2. United Nations Children's Fund. Estratégia para melhorar a nutrição de crianças e mulheres nos países em desenvolvimento. New York: United Nations Children's Fund; 1990.

3. United Nations Children's Fund/World Health Organization. Prevention and control of iron deficiency anaemia in women and children. Geneva: United Nations Children's Fund/World Health Organization; 1999.
4. Pan American Health Organization. Flour fortification with iron, folic acid and vitamin B12. Santiago: Pan American Health Organization; 2003.

5. Stoltzfus RJ. Rethinking anaemia surveillance. Lancet 1997; 349:1764-6.

6. Batista Filho M, Rissin A. A transição nutricional no Brasil: tendências regionais e temporais. Cad Saúde Pública 2003; 19 Suppl 1:S181-91.

7. United Nations Children's Fund. Preventing iron deficiency in women and children: technical consensus on key issues. New York: United Nations Children's Fund; 1998. 
8. Pena-Rosa JP, Viteri FE. Effects of routine oral iron supplementation with or without folic acid for woman during pregnancy (Cochrane Review). In: The Cochrane Collaboration, Issue 2, 2007. Oxford: Oxford Update Software.

9. Reveiz L, Gyte GML, Cuervo LG. Treatments for iron-deficiency anaemia in pregnancy (Cochrane Review). In: The Cochrane Collaboration, Issue 2, 2007. Oxford: Oxford Update Software.

10. Souza AI, Batista Filho M, Ferreira LOC, Figueiroa JN. Efetividade de três esquemas com sulfato ferroso para tratamento de anemia em gestantes. Rev Panam Salud Pública 2004; 15:313-9.

11. Ferreira LOC, Batista Filho M, Lopes MCS. Uso diário e semanal de sulfato ferroso no tratamento de anemia em mulheres no período reprodutivo. Cad Saúde Pública 1999; 15:799-808.

12. Ridwan E, Schultink W, Dillon D, Gross R. Effects of weekly iron supplementation on pregnant Indonesian women are similar to those of daily supplementation. Am J Clin Nutr 1996; 63:884-90.

13. Rose MB. Ferrous sulfate: drug information. http:// www.uptodate.com (accessed on 20/Mar/2006).

14. Ekström ECM, Kavishe FP, Habicht JP, Frongillo Jr. EA, Rasmussen KM, Hemed L. Adherence to iron supplementation during pregnacy in Tanzania: determinants and hematologic consequences. Am J Clin Nutr 1996; 64:368-74.

15. Kumar A, Jain S, Singh NP, Sing T. Oral versus high dose parenteral iron supplementation in pregnancy. Int J Gynecol Obstet 2005; 89:7-13.

16. Troost, FJ, Saris WHM, Haenen GRMM, Bast A, Brummer RJM. New method to study oxidative damage and antioxidants in the human small bowel: effects of iron application. Am J Physiol Gastrointest Liver Physiol 2003; 285:354-9.

17. Braga JAP, Fisberg M. Anemia ferropriva. In: Nóbrega FJ, editor. Distúrbios da nutrição. Rio de Janeiro: Editora Revinter; 1998. p. 287-95.

18. Atalah SE, Catillo LC, Castro SR, Áldea PA. Propuesta de um nuevo estándar de evaluación nutricional embarazadas. Rev Med Chil 1997; 125:1429-36.

19. Symonds E, Radden H, Cellier K. Controlled-release iron therapy in pregnancy. Aust N Z J Obstet Gynaecol 1969; 9:21-5.

20. Cogswell ME, Parvanta I, Ickes L, Yip R, Brittenham GM. Iron supplementation during pregnancy, anemia, and birth weight: a randomized controlled trial. Am J Clin Nutr 2003; 78:773-81.

21. Eskeland B, Malterud K, Ulvik RJ, Hunskaar S. Iron supplementation in pregnancy: is less enough? A randomized, placebo controlled trial of low-dose iron supplementation with and without heme iron. Acta Obstet Gynecol Scand 1997; 76:822-8.
22. Hulley SB, Newman TB, Cummings SR. Escolhendo os sujeitos do estudo: especificação, amostragem e recrutamento. In: Hulley SB, editor. Delineando a pesquisa clínica - uma abordagem epidemiológica. São Paulo: Editora Artmed; 2003. p. 43-4.

23. Yip R. Iron supplementation during pregnancy: is it effective? Am J Clin Nutr 1996; 63: 853-5.

24. Shatrugna V, Raman L, Kailash U, Balakrishna N, Rao KV. Effect of dose and formulation on iron tolerance in pregnancy. Natl Med J India 1999; 12:18-20.

25. Young MW, Lupafya E, Kapenda E, Bobrow EA. The effectiveness of weekly iron supplementation in pregnant women of rural Northern Malawi. Trop Doct 2000; 30:84-8.

26. Zavaleta N, Respico G, Garcia T. Efficacy and acceptability of two iron supplementation schedules in adolescent school girls in Lima, Peru. J Nutr 2000; 130 Suppl:462-4.

27. Zavaleta N, Caulfield LE, Garcia T. Changes in iron status during pregnancy in Peruvian women receiving prenatal iron and acid supplements with or without zinc. Am J Clin Nutr 2000; 71:956-61.

28. O'Brien KO, Zavaleta N, Caunfield LE, Yang DX, Abrams AS. Influence of prenatal iron and zinc supplements on supplemental iron absorption, red blood cell iron incorporation, and iron status in pregnant Peruvian women. Am J Clin Nutr 1999; 69:509-15.

29. Meier PR, Nickerson HJ, Olson KA, Berg RL, Meyer JA. Prevention of iron deficiency anemia in adolescent and adult pregnancies. Clin Med Res 2003; 1:29-36.

30. Makrides M, Crowther CA, Gibson RA, Gibson RS, Skeaff CM. Efficacy and tolerability of lowdose iron supplements during pregnancy: a randomized controlled trial. Am J Clin Nutr 2003; 78: 145-53.

31. Ferreira MLM, Ferreira LOC, Silva AA, Batista Filho M. Efetividade da aplicação do sulfato ferroso em doses semanais no Programa Saúde da Família em Caruaru, Pernambuco, Brasil. Cad Saúde Pública 2003; 19:375-81.

32. Cardoso MA, Penteado MVC. Intervenções nutricionais na anemia ferropriva. Cad Saúde Pública 1994; 10:231-40.

Submitted on $04 / \mathrm{Jan} / 2008$

Final version resubmitted on 27/Mar/2008

Approved on 16/Jul/2008 